\title{
Application Of Thermal Infrared Remote Sensing Technique For Determining Spatiotemporal Changes In Urban Surface Temperature: Rivers State, Nigeria
}

\author{
Eze Promise I. And Lawson Nwidum
}

Application Of Thermal Infrared Remote Sensing Technique For Determining Spatiotemporal Changes In Urban Surface Temperature: Rivers State, Nigeria

DOI: 10.29322/IJSRP.11.10.2021.p11870

http://dx.doi.org/10.29322/IJSRP.11.10.2021.p11870

\begin{abstract}
The built environment in Rivers State Nigeria have in recent years witnessed high rate of urban surface temperatures which is attributed to global warming, climate change and the depletion of the ozone layer. The environment absorbed high temperature during the day time and sometimes could not completely emit it during evening and night as a result of factors responsible for this phenomenon called "Urban Heat Island". This study is aimed at determining and forecasting of urban surface temperature in Rivers State, Nigeria; with the objectives of extracting the urban surface temperature of the study area using thermal infrared remote sensing techniques, and forecasting of the trends in urban surface temperature of the study area for a period of twenty years. The Thermal Infrared (TIR) remote sensing and Geospatial Information System (GIS) techniques were adopted for this research. Urban Surface Temperatures were obtained through extraction of urban surface temperature value of the study area in form of Digital Number (DN), conversion of DN to Spectral radiance using the Spectral radiance equation, conversion of radiance to temperature kelvin using the thermal equation and conversion of temperature Kelvin to temperature Celsius using the Temperature Celsius equation. The data were processed, analyzed and modeled using ESRI's ArcGIS 10.1 spatial data processing software, predictions were made using Least Squares linear prediction model. The research findings revealed that the Urban Surface Temperature of the study area from epochs of year $2000-2020$ increase by $16 \%$ with varying average Temperatures in degree Celsius $\left({ }^{\circ} \mathrm{C}\right)$ of $21.92,23.39,23.73,24.83$ and 25.12 respectively. It was also noted that an average urban surface temperatures of $26.28^{\circ} \mathrm{C}, 27.12^{\circ} \mathrm{C}, 27.95^{\circ} \mathrm{C}$, and $28.78^{\circ} \mathrm{C}$, were forecast for year $2025,2030,2035$, and 2040 respectively if nothing is done to forestall the increase in urban surface temperature. The research findings justified the need to adopt the thermal infrared remote sensing technique in extracting and monitoring spatiotemporal changes in urban surface temperatures of any area but not neglecting other reliable methods, afforestation, urban-rural migration as well as effective urban development and physical planning laws were recommended to reduce possible causes of high urban surface temperature.
\end{abstract}

Index Terms- Thermal, Temperature, Forecast, Infrared

\section{BACKGROUND OF STUDY}

$\mathrm{G}$ lobal warming which refers to the rise in global temperatures occurs mainly due to increasing concentrations in green house atmosphere. Climate change has also resulted to increase surface temperature as a result of depletion of the ozone layer (Favratto, 2016). An observed rise in the near surface temperatures due to persistence rural- urban migration which is a major cause of urbanization in different parts of the world has become one of the numerous identified global environmental changes. This phenomenon known as Urban Surface Temperature is also referred to what researchers called Urban Heat Island (EPA, 2019). Global population trends show a relative bias towards rural-urban migration. In a relatively as the world's population residing in urban areas had passed 50\% by 2018 , and the percentage has been forecast to stand at $68 \%$ by 2050 (United Nation (UN), 2018). The increase in Urban Surface Temperatures has become a global challenge capable of impacting negatively on the smooth running and habitability of the urban environments, two factors identified as major causes or contributors to high urban surface temperatures are urbanization and human activities due to the changes they induce on the physical characteristics of the earth's surface and the alterations to near-surface flow and radioactive fluxes. Physical parameters on the earth's surface which undergo the changes include the thermal capacity, moisture, and heat conductivity ( Rinkesh, 2020). The study Area Rivers State, Nigeria has witnessed persistence city growth and urban development due to increasing population, and much of these growths are unplanned and unregulated. Major Local Government such as Port Harcourt city been the capital city, Obio/Akpor, Ikwerre and Bonny are fully or relatively urbanized, with little or no physical planning and regulated urban development which has resulted to increase urban surface temperature due to clustered urban settlement, deforestation, and other human activities. This prompted the need for this research as to determine and forecast the trends of urban surface temperature over five epochs. 


\section{STUDY AREA}

The Study area covers Obio-Akpor, Port Harcourt City, Eleme, Ogu Bolo, Okrika, and Bonny Local Government Area of Rivers State, Nigeria (Figure 2.1)._The study area were selected due to the observed massive urbanization, population growth, gas flaring and illegal oil refining in the last two decades in these part of Rivers State. These Local Government Areas which constitute the study area are host of multi-national oil companies, two seaports, citadel of learning, and industrial hubs. .

The study area is generally a lowland area with average elevation below 30 metres above sea level, the land use/ land cover in the area include: Water body, Built-up areas, Mangrove vegetation along rivers and creeks shorelines, Vegetation and wetland, the mean temperature ranges between $30.0^{\circ} \mathrm{C}-33.0^{\circ} \mathrm{C}$ and annual rainfall ranges between $2100 \mathrm{~mm}-4600 \mathrm{~mm}$ as reported by (NIMET, 2011). It is located between latitudes $4^{\circ} 24^{\prime} \mathrm{N}$ and $4^{\circ} 533^{\prime} \mathrm{N}$ and longitudes $6^{\circ} 57^{\prime} \mathrm{E}$ and $7^{\circ} 20^{\prime} \mathrm{E}$ and covers approximate surface area of 145642.1 hectares.

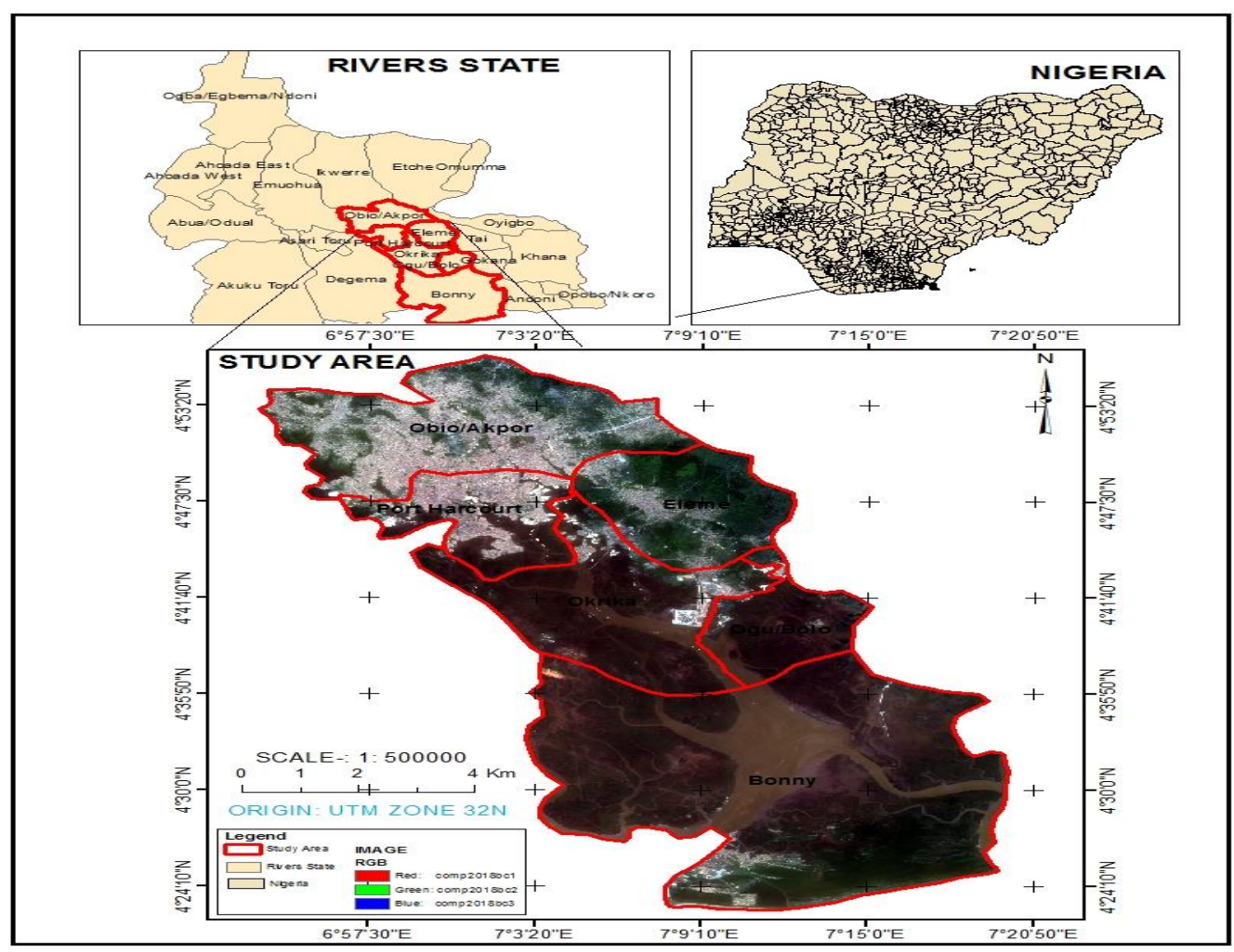

Figure 1.2: Image showing the Study Area. Source: SPOT, 2020

\section{Aim of Study:}

The aim of study to determine and forecast the trends of urban surface temporature in Rivers State, Nigeria; Objectives of Study

i. $\quad$ Extracting the urban surface temperature of the study area using thermal infrared remote sensing techniques,

ii. $\quad$ Forecasting of the trends in urban surface temperature of the study area for a period of twenty years using least squares linear predictive model.

\section{MATERIALS AND METHODS}

Software and Hardware used were set of computer with processor Intel® Core TM i3-3110M CPU @ 2.40GHZ, 4.00GB RAM, and 64-bit operating system. The Computer contains all the applications used in this work. ESRI's ArcGIS 10.1 version 2012 and Microsoft Excel ArcGIS were used for Processing, modeling and Data Analysis.

This study was carried out using Thermal Infrared Remote (TIR) sensing and Geographic Information System (GIS) Techniques. Thermal infrared remote sensing is the branch of Remote Sensing that deals with the acquisition, processing and interpretation of data acquired primarily in the thermal infrared (TIR) region of the electromagnetic (EM) spectrum. In thermal remote sensing, the radiations 'emitted' from the surface of the earth (target) is been measured, as opposed to optical remote sensing where the radiations 'reflected' by the target under consideration is measured (Van Zyl \& Elachi, 2000)

TIR sensing method was used to acquire Urban Surface Temperature of the Study area at 30 meters interval across various land use and Land cover in the study area. 
The method was adopted due to its relevancy of acquiring Urban Surface Temperature across various Land use/land over (LU/LC) in the study area and its capability to provide time series data of different epochs to enable proper monitoring and modeling of the Urban Heat Island of the Study area.

\section{Data Acquisition}

The Data used for the study was obtained from LANDSAT ETM and LANDSAT OLI sensors that acquire LU/LC images and Urban Surface temperature data emitted by objects in the study area and store the information as a digital number (DN) thermal band (B2, B3, B4, B5, B61 and B10). LANDSAT TM images were obtained from 5 different epochs: 2000,2005,2010,2015 and 2020 respectively. See Table 3.1. The LANDSAT images were rectified to the UTM projection system (datum WGS84, zone 32N).

Table 3.1 Characteristics of Landsat satellite image used for the study.

\begin{tabular}{|c|c|c|c|c|}
\hline Sensor & Acqui. Date & Band & Resolution (m) & Source \\
\hline Landsat ETM & $17 / 12 / 2000$ & $\begin{array}{l}\text { B2=GREEN } \\
\text { B3= RED } \\
\text { B4= NIR } \\
\text { B61=TIR }\end{array}$ & $30 \times 30$ & http://glovis.usgs.gov/ \\
\hline Landsat ETM & $13 / 01 / 2005$ & $\begin{array}{l}\text { B2=GREEN } \\
\text { B3= RED } \\
\text { B4= NIR } \\
\text { B61=TIR }\end{array}$ & $30 \times 30$ & http://glovis.usgs.gov/ \\
\hline Landsat ETM & $01 / 12 / 2010$ & $\begin{array}{l}\text { B2=GREEN } \\
\text { B3= RED } \\
\text { B4= NIR } \\
\text { B61 =TIR }\end{array}$ & $30 \times 30$ & http://glovis.usgs.gov/ \\
\hline Landsat ETM & $27 / 12 / 2015$ & $\begin{array}{l}\text { B2=GREEN } \\
\text { B3 }=\text { RED } \\
\text { B4= NIR } \\
\text { B61=TIR }\end{array}$ & $30 \times 30$ & $\underline{\text { http://glovis.usgs.gov/ }}$ \\
\hline Landsat OLI & $18 / 01 / 2020$ & $\begin{array}{l}\text { B3=GREEN } \\
\text { B4= RED } \\
\text { B5= NIR } \\
\text { B10=TIR }\end{array}$ & $30 \times 30$ & http://glovis.usgs.gov/ \\
\hline
\end{tabular}

Source: Author, 2021

\section{Processing of Urban Surface Temporature}

The first process was to convert the DNs to radiance values using the bias and gain values specific to the individual pixel. This is followed by converting the radiance data to degrees in Kelvin and finally converting the temperature in Kelvin to the temperature Celsius.

\section{Converting the Digital Number (DN) to Spectral Radiance (L $\lambda)$ :}

Radiance $(\mu \mathrm{m})$ in band 6,61 and 10 were calculated from digital numbers (DN) using standard NASA equations. The spectral radiance $(\mathrm{L} \lambda)$ was calculated as follows

Where:

$$
\mathrm{L} \lambda=\frac{\mathrm{L}_{\mathrm{MAX} \lambda}-\mathrm{L}_{\mathrm{MAX} \lambda}}{\mathrm{Q}_{\text {CALMAX }}-\mathrm{Q}_{\text {CALMIN }}}\left(\mathrm{DN}_{\mathrm{QCALMIN}}\right)+\mathrm{L}_{\mathrm{MIN}} \lambda
$$

$$
\mathrm{L} \lambda=\text { Spectral Radiance }
$$

$\mathrm{L}_{\mathrm{MAX}} \lambda,=$ maximum spectral radiance for the band

$\mathrm{L}_{\mathrm{MIN}} \lambda=$ minimum spectral radiance for the band

$\mathrm{Q}_{\text {CALMAX }}=$ maximum quantize calculated for the band

$\mathrm{Q}_{\text {CALMIN }}=$ minimum quantize calculated for the band

$\mathrm{DN}=$ pixel DN value.

\section{Converting Spectral Radiance (L $\lambda$ ) to Temperature in Kelvin (K)}

The ETM+ thermal band data could be converted from spectral radiance to Temperature in Kelvin (K) using the expression below: 


$$
T=\frac{K_{2}}{\ln \left(\frac{k_{1}}{L_{\gamma}}+1\right)}
$$

Where:

$$
\mathrm{T}=\text { Temperature "Kelvin", }
$$

$\mathrm{K}_{1}$ and $\mathrm{K}_{2}$ are constants. $\mathrm{K}_{1}$ and $\mathrm{K}_{2}$ values can be extracted from the Meta data file of the downloaded thermal Image.

\section{Converting Temperature from Kelvin to Celsius}

The temperature in Celsius was calculated using the following equation:

$\mathrm{T}(\mathrm{C})=\mathrm{T}-273.13$

Where:

$\mathrm{T}(\mathrm{C})=$ Temperature "Celsius,"

$\mathrm{T}=$ Temperature "Kelvin",

273.13 = Zero Temperature "Kelvin".

Conversion procedures for images acquired from Digital number (DN) to Spectral Radiance-Temperature Kelvin-Celsius For LANDSAT 2020 OLI, TOA radiance is computed using the formula,

$\mathrm{L}^{\lambda}=\mathrm{M}_{\mathrm{L}} \times \mathrm{Q}_{\mathrm{cal}}+\mathrm{A}_{\mathrm{L}}$

Where:

$\mathrm{L}_{\lambda}=$ spectral radiance in $\mathrm{Wm}^{-2} \mathrm{Sr}^{-1}$

$\mathrm{M}_{\mathrm{L}}=$ radiance multiplicative scaling factor for the band

$\mathrm{Q}_{\text {cal }}=\mathrm{L} 1$ pixel value in $\mathrm{DN}$ and

$\mathrm{A}_{\mathrm{L}}=$ radiance additive scaling factor for the band

Here band 10 of the 2020 LANDSAT data was used and the parameters are:

$\mathrm{M}_{\mathrm{L}}=0.000334$

$\mathrm{A}_{\mathrm{L}}=0.1$

Substituting the values in the equation to computes spectral radiance image.

The surface temperature was computed from the TOA radiance image using Equation 3.2

$\mathrm{K}_{1}$ and $\mathrm{K}_{2}$ are the thermal conversion constant for band 6 and 10. The parameters $\mathrm{M}_{\mathrm{L}}, \mathrm{A}_{\mathrm{L}}, \mathrm{K}_{1}$, and $\mathrm{K}_{2}$ are obtained from the LANDSAT header file. The thermal constants for the TM, ETM+ and OLI were given in table 3.2

Table 3.2 Thermal conversion constants for different LANDSAT Satellite sensors.

\begin{tabular}{llll}
\hline BAND & SENSOR & K1 & K2 \\
\hline 6 & ETM and ETM+ & 600.0900 & 1282.7100 \\
\hline 10 & OLI & 774.8853 & 1321.0789 \\
\hline
\end{tabular}

From table 3.2, the parameters are:

$\mathrm{K} 1=774.8853$

$\mathrm{K} 2=1321.0789$

By substituting the values in the equation (3.2), Urban Heat Island for band 10 in the study area was computed in Kelvin temperature scale. The computations were done in ESRI's ArcGIS 10.1 software.

Accordingly, the computed temperature in Kelvin scale was converted to temperature in Celsius scale using equation (3.3). The Data processing interface in ESRI's ArcGIS 10.1 software application is shown in Figure 3.2 


\section{Screen Prints of 2020 image}

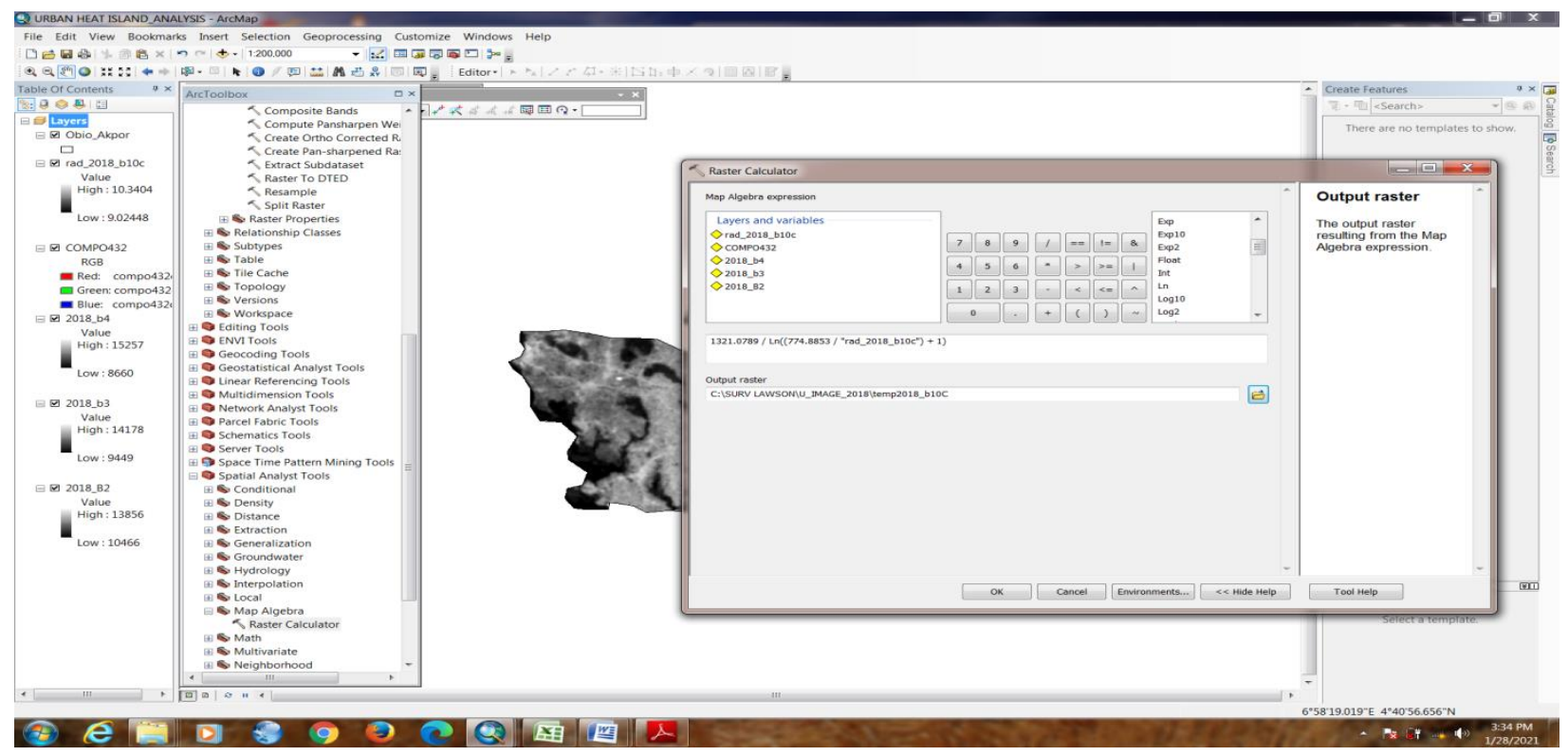

Figure 3.2: showing Screen shot of 2020 image in ESRI's ArcGIS 10.1 software application.

For the Enhanced Thematic Mapper Plus (ETM+), TOA radiance in $\mathrm{Wm}^{-2} \mathrm{Sr}^{-1}$, is computed using equation (3.1) computing for LANDSAT TM 2000 using band 6, the values are

$\mathrm{L}_{\mathrm{MAX} \lambda},=15.303 . \mathrm{L}_{\mathrm{MIN} \lambda}=1.238 . \quad \mathrm{Q}_{\mathrm{CALMAX}}=255 . \quad \mathrm{Q}_{\mathrm{CALMIN}}=1$.

By substituting the values in equation (3.1) together with the raw image data, the radiance image was computed.

Now converting radiance image to brightness temperature, thermal equation (Equation 3.2) was introduced:

Where:

$\mathrm{K}_{1}=607.7600$ and $\mathrm{K}_{2}=1260.5600$

Converting to Temperature Celsius, equation (3.3) was introduced.

Also computing for LANDSAT 2005 ETM using band 61 (thermal band), the values of the parameters are:

$\mathrm{L}_{\mathrm{MAX} \lambda}=17.04 . \mathrm{L}_{\mathrm{MIN} \lambda}=0 . \quad \mathrm{Q}_{\mathrm{CALMAX}}=255 . \quad \mathrm{Q}_{\mathrm{CALMIN}}=1$.

Substituting the values in Equation (3.1), the Digital Number (DN) is converted to radiance image.

Now is to convert radiance image to brightness temperature by utilizing thermal equation (3.2). The thermal constants for ETM area:

$\mathrm{K}_{1}=600.0900$

$\mathrm{K}_{2}=1282.7100$

Converting to Temperature Celsius, equation (3.3) was introduced.

Also computing for LANDSAT 2010 ETM using band 61 (thermal band), the values of the parameters are:

$\mathrm{L}_{\mathrm{MAX} \lambda},=17.04$

$\mathrm{L}_{\mathrm{MIN} \lambda}=0$

$\mathrm{Q}_{\text {CALMAX }}=255$

$\mathrm{Q}_{\mathrm{CALMIN}}=1$

Substituting the values in the radiance equation (3.1), radiance image is derived.

Now is to convert radiance image to brightness temperature by utilizing thermal equation (3.2). The thermal constants for ETM area:

$\mathrm{K}_{1}=600.0900$

$\mathrm{K}_{2}=1282.7100$

Converting to Temperature Celsius, equation (3.3) was employed.

In the same way, computing for LANDSAT 2015 OLI using band 10 (which is the sensor thermal band), the values of the parameters used are giving below:

$\mathrm{M}_{\mathrm{L}}=0.000334$ and $\mathrm{A}_{\mathrm{L}}=0.1$.

Substituting the values in the model (equation 3.4) to computes spectral radiance image as described earlier.

Urban Heat Island was also computed from the TOA radiance image using the formula stated earlier (equation 3.2).

In the model, the thermal Constance for OLI sensor are:

$\mathrm{K}_{1}=774.8853$ and $\mathrm{K}_{2}=1321.0789$

Converting to Temperature Celsius, equation 3.3 was used. 


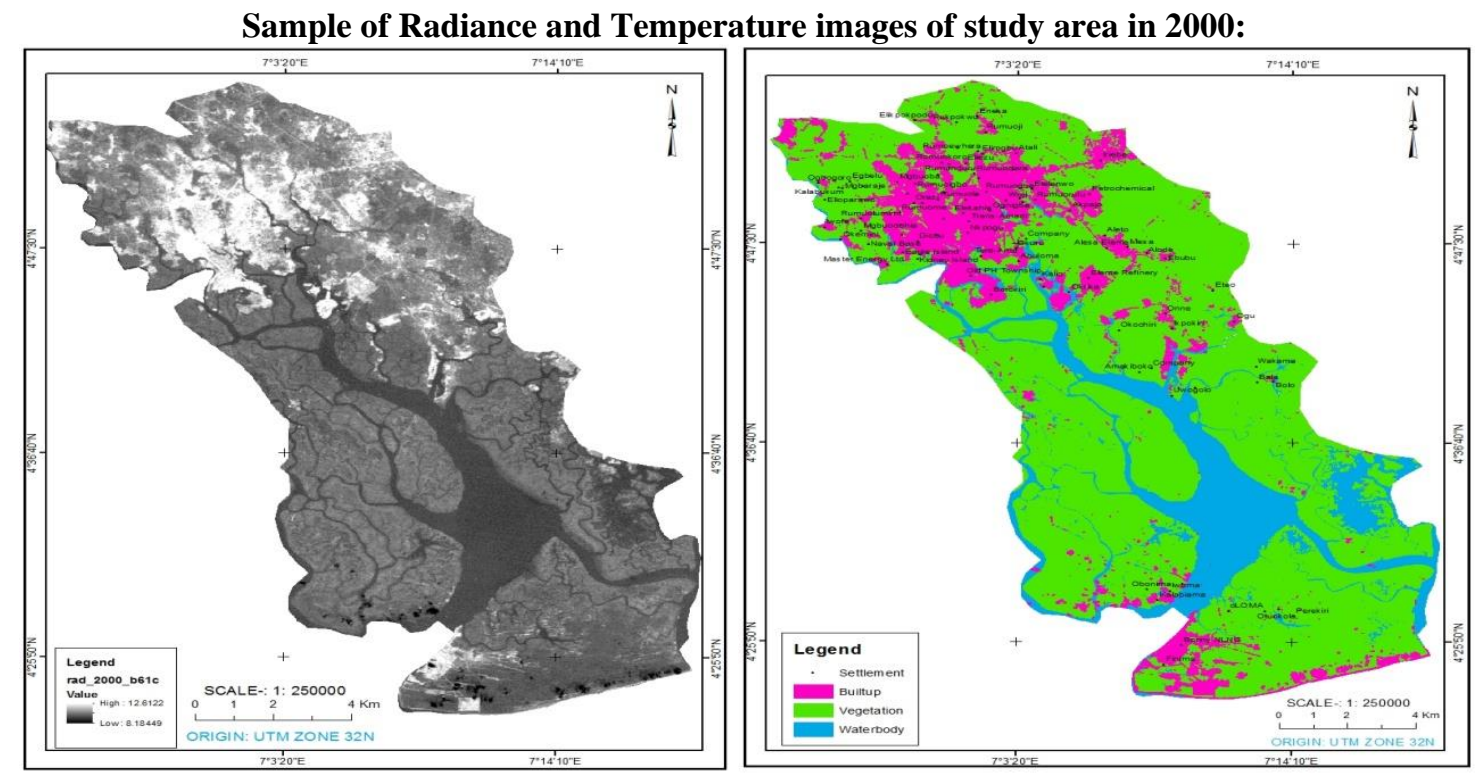

Figure 3.3A Radiance image sample

Figure 3.3B: Temperature image sample Source: Author, 2021

IV. RESUlts AND DisCUSSIONS

Urban Surface Temperature Maps of the study area for epochs of 2000-2020

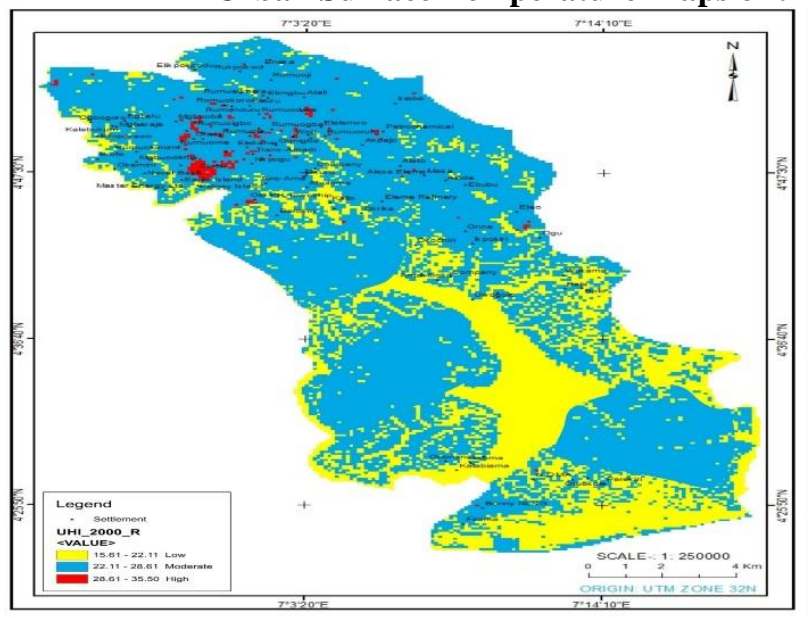

Fig. 4.1: Temperature Map of Year 2000.

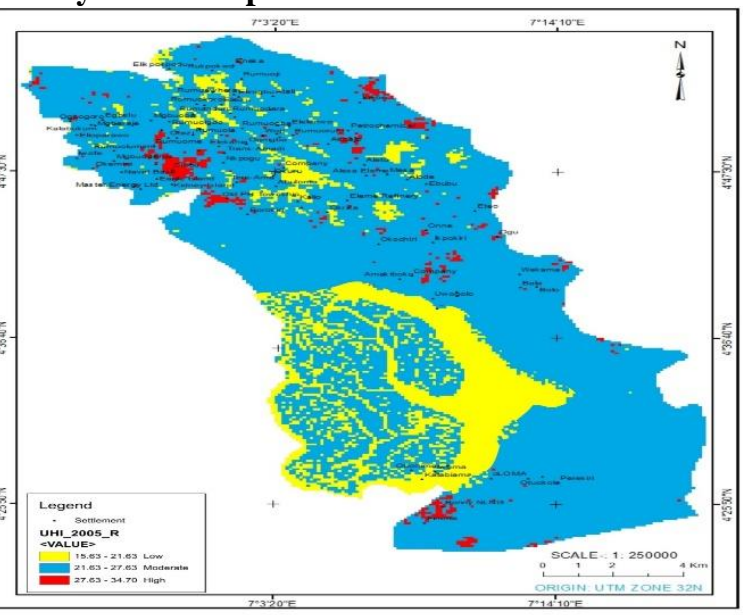

Fig. 4.2: Temperature Map of Year 2005 


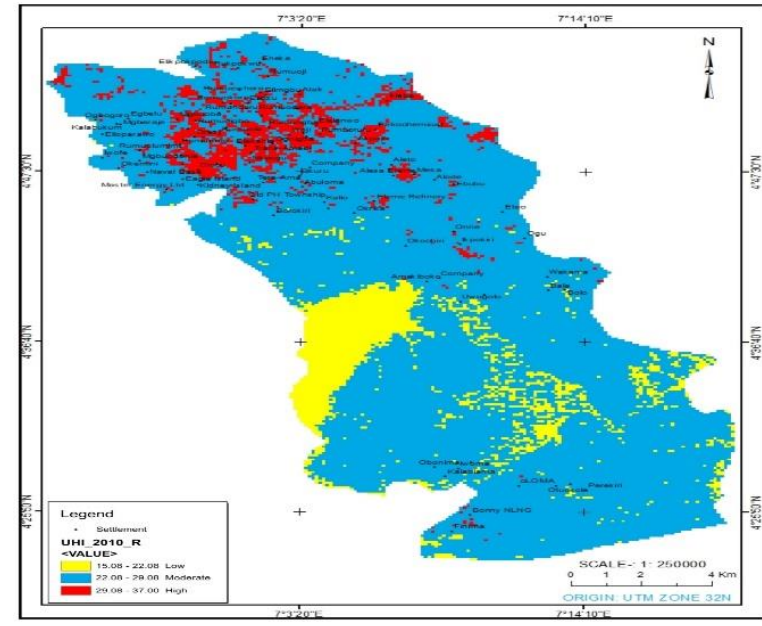

Fig. 4.3: Temperature Map of Year 2010.

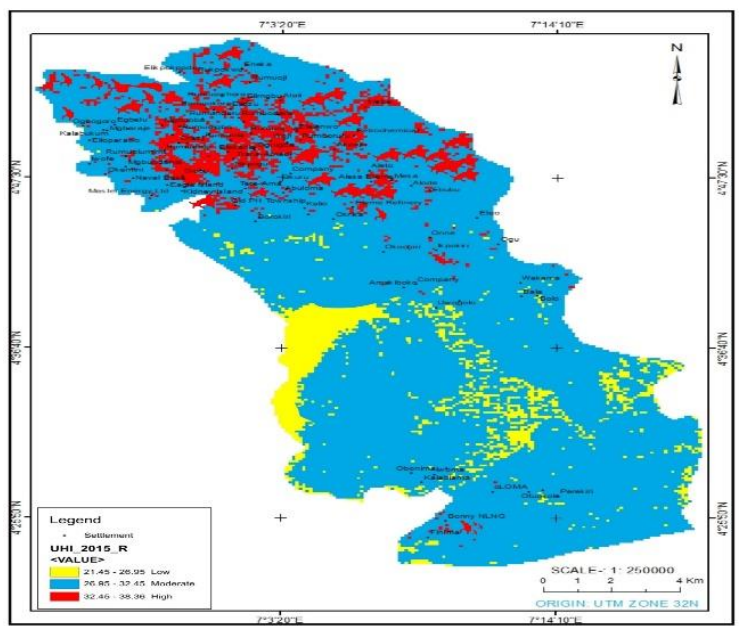

Fig. 4.4: Temperature Map of Year 2015

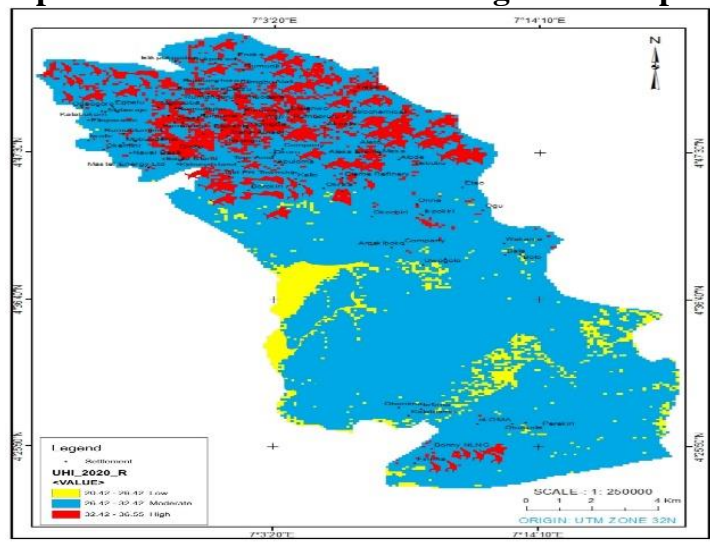

. Fig. 4.5: Temperature Map of Year 2020.

Table 4.1: Epoch Based Average, Maximum and Minimum Urban Surface Temperature

\begin{tabular}{llll}
\hline UHI & AVERAGE $\left({ }^{\circ} \mathrm{C}\right)$ & MAXIMUM $\left({ }^{\circ} \mathrm{C}\right)$ & MINIMUM $\left({ }^{\circ} \mathrm{C}\right)$ \\
\hline 2000 & 21.92 & 35.50 & 15.61 \\
2005 & 23.39 & 34.70 & 15.63 \\
2010 & 23.73 & 37.00 & 15.08 \\
2015 & 24.83 & 38.36 & 21.45 \\
\hline 2020 & 25.12 & 36.55 & 20.42 \\
\hline
\end{tabular}

Source: Author, 2021

Figure 4.1, 4.2, 4.3, 4.4 and 4.5 shows the Urban Surface Temperature Maps of the Study Area epochs (Year) 2000 - 2020. The Urban Surface Temperatures of the study area are inconsistence over the epochs under study. The red doted colour in the classified satellite imagery shows that there is high temperature record in parts of Port Harcourt, Obio/Akpor such as Diobu, Old PH Township, Nkpogu, Rumuoigbo, Elekahia, Rumuola, Rumuodara, and also parts of Eleme which includes Akpajo, Alesa communities, this may be as a function of the urbanized nature of these areas. However, Rural Communities and Riverine Communities which cut across Ikwerre, Emohua, Degema and Borny Local Government Area of Rivers State recorded a relatively lower temperature across the epochs.

Table 4.1 shows the Average, Maximum and Minimum temperature in the study area in five Epochs (Year) 2000, 2005, 2010, 2015, and 2020. These temperature data were captured at 30 meters grid across various Land use and Land cover in the study area. The Average shows the overall Urban Surface trends in each epoch under study which ranges from 2000 to 2020 with temperature increase at $16 \%$ from $21.9^{\circ} \mathrm{C}$ to $25.12^{\circ} \mathrm{C}$. This increase in urban surface temperature is may be attributed to the increasing urbanisation that is taking place in part of the study area such as Obio/Akpor, Port Harcourt City, Ikwerre, and Eleme Local Government Area and the high concentration of Green House Gases emitted into the environment by burning of fossil fuel and gas flaring from petro-chemical companies and illegal oil activities in part of the study area such as Okrika, Ogu Bolo, Eleme, and Bonny Local Government Area. 


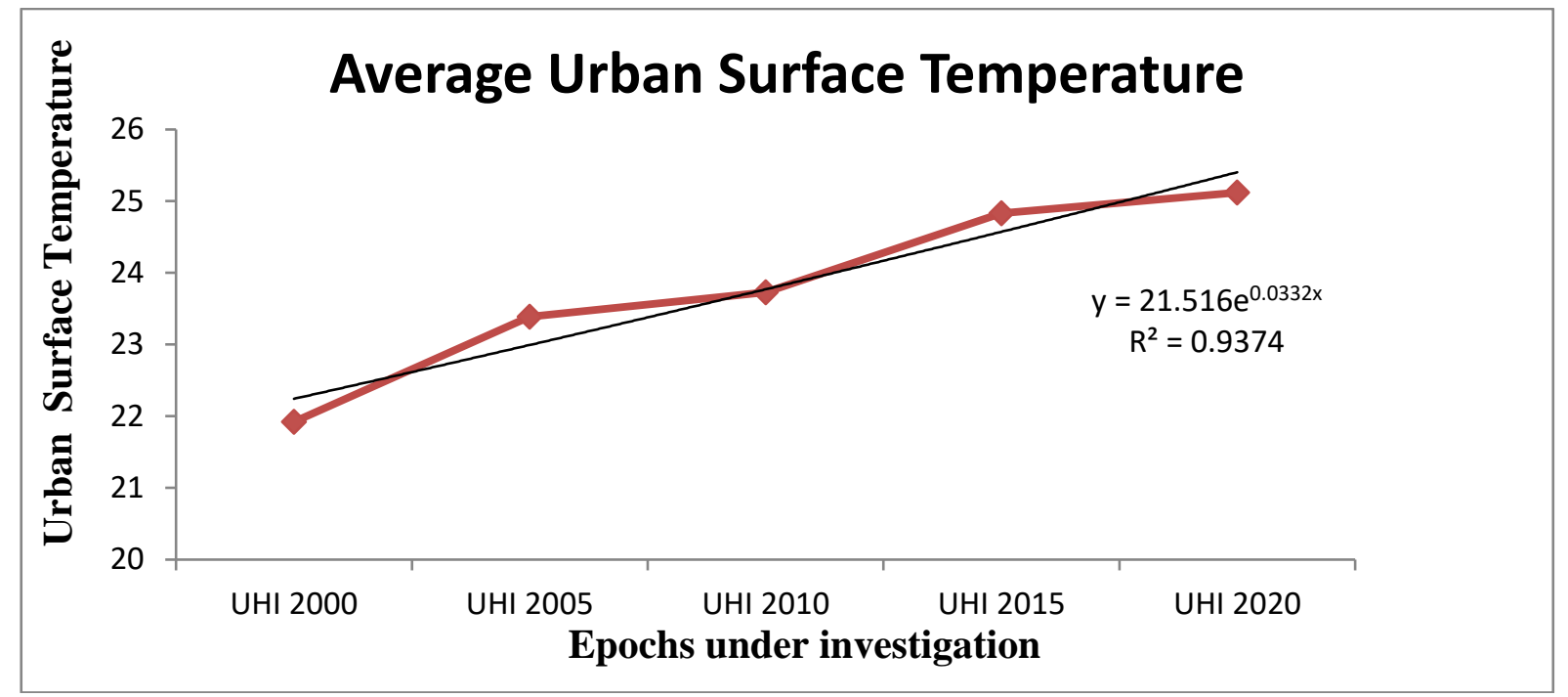

Figure 4.6: Graphical representation of Average Urban Surface Temperature for each Epoch. Source: Author, 2021

Figure 4.6 above shows the graphical representation of average Urban Surface Temperature of the study area for epochs of 20002020. The graph shows a relatively linear trend in Urban Surface Temperature variation of the study area from $2000-2020$.

In 2000, the Average Urban Temperature of the study area was $21.92^{\circ} \mathrm{C}$, the value increase to $23.39^{\circ} \mathrm{C}$ in 2005 with a difference of $1.47^{\circ} \mathrm{C}$. The temperature of year 2005 increased to 23.73 in 2010 . Accordingly, the temperature of year 2010 increased to $24.83^{\circ} \mathrm{C}$ in year 2015 with temperature difference of $1.1^{\circ} \mathrm{C}$ and temperature of 2015 increased to $25.12^{\circ} \mathrm{C}$ with a difference of $0.36^{\circ} \mathrm{C}$. The analysis shows increasing trend in the Urban Surface Temperature of the study area across various land use and land cover in the various years under investigation.

In addition the results revealed that there is a $16 \%$ (percent) increase in Average Urban Surface Temperature between the years 2000 and 2020. The predictive linear model indicates that there is a strong positive correlation in Urban Surface Temperature between the years 2000 to 2020. And this model will be used to forecast Urban Surface Temperature within the study Area.

\section{Forecasting of Urban Surface Temperature for Period of 20years}

The predictive model adopted in this research is Least Squares linear predictive model. The method of Least squares makes use of redundant observation in the mathematical modeling of a given problem with a view to minimize the sum of the squares of discrepancies between the observations and their most probable value (adjusted values subject to the prevailing mathematical model (Opuaji, 2017). The average urban surface temperatures of the epochs under study were used to predict and forecast future temperature for a period of twenty years, since the graphical representation shows a linear trend, the mathematical model for a straight line graph as given in equation 4.1 below was used as the predictive model.

$y=m x+c$

Where:

$\mathrm{y}=$ year

$\mathrm{x}=$ temperature value

$\mathrm{m}=$ gradient of the curve

$\mathrm{c}=$ intercept

From the data in table 4.2, using the method of least squares for observation equations,

The functional model was developed as

$$
\left[\begin{array}{l}
2000=21.92 m+c \\
2005=23.39 m+c \\
2010=21.92 m+c \\
2015=21.92 m+c \\
2020=21.92 m+c
\end{array}\right]
$$


The design matrix $\mathrm{A}$ is given as

$A=\left[\begin{array}{ll}21.92 & 1 \\ 23.39 & 1 \\ 23.73 & 1 \\ 24.83 & 1 \\ 25.12 & 1\end{array}\right]$

Physical Observed parameters/original values ( $\mathbf{L}^{\mathbf{b})}$

$L^{b}=\left[\begin{array}{l}2000 \\ 2005 \\ 2010 \\ 2015 \\ 2020\end{array}\right]$

Weight matrix

$P=1$

Least squares estimate of the prediction parameters,

$$
\stackrel{\Delta}{X}=\left[\begin{array}{l}
m \\
c
\end{array}\right]=\left(A^{T} P A\right)^{-1} A P L^{b}
$$

This gives us the corrections to approximate values for $(m)$ and $(c)$

Using Mat Lab coding,

$$
\stackrel{\Delta}{X}=\left[\begin{array}{c}
0.0000069 \\
0.00186678
\end{array}\right]
$$

The prediction model; $\quad \mathrm{T}_{\text {year }} \quad=\frac{[\text { year }-\boldsymbol{c}]}{m}$

Where $\mathrm{T}=\mathrm{UHI}$ temperature for predicted year.

For year 2025; $\mathrm{T}_{\mathbf{2 0 2 5}}=[2025-0.0018621] / 0.0000060=26.28^{0} \mathrm{C}$

For year 2030; $\left.\mathrm{T}_{\mathbf{2 0 3 0}}=2030-0.0018621\right] / 0.0000060=27.1198^{\circ} \mathrm{C}$

For year 2035, $\mathrm{T}_{\mathbf{2 0 3 5}}=[2035-0.0018621] / 0.0000060=27.95^{\circ} \mathrm{C}$

For year 2040, $\mathrm{T}_{\mathbf{2 0 4 0}}=[2040-0.0018621] / 0.0000060=28.78^{0} \mathrm{C}$

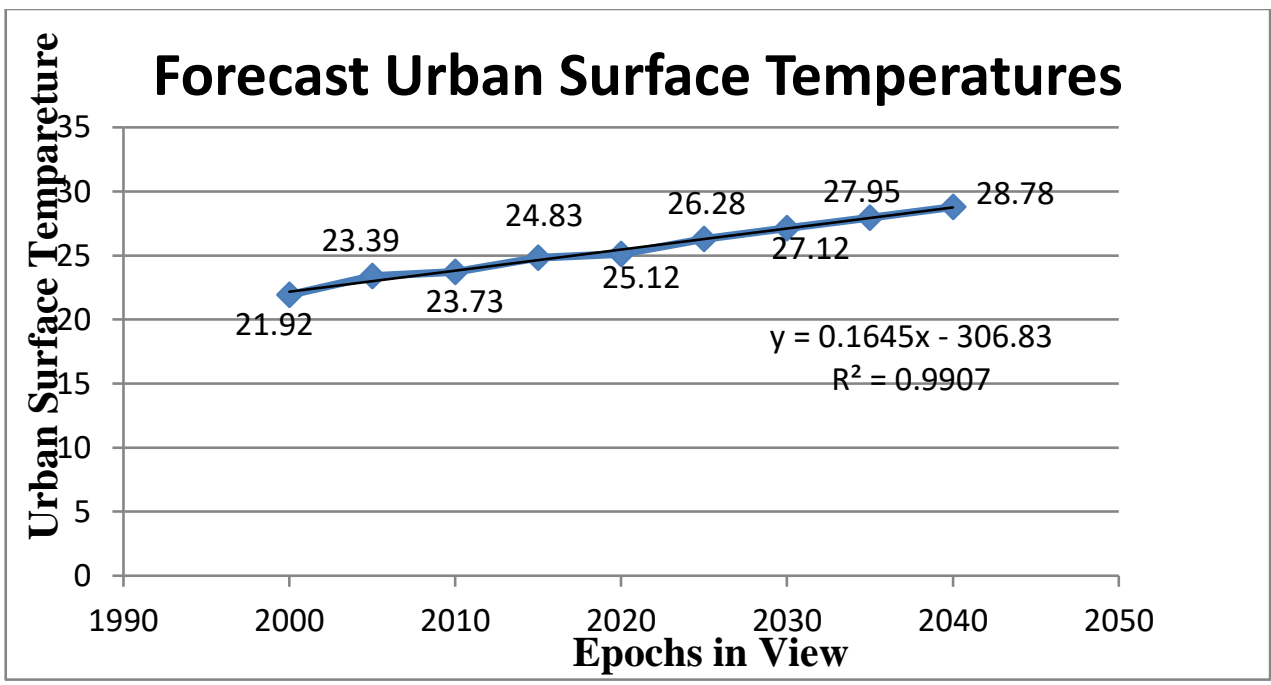

Fig. 4.7: forecast average urban surface temperature for a period of 20 years 
From figure 4.7, it is clear that the average urban surface temperature of the study area will continue to increase if no action is taken to evaluate the perceived causes of these high temperatures in the study area. The forecast results indicate shows that an average urban surface temperatures of 26.28, 27.12, 27.95 and 28.78 will occur in year 2025, 2030, 2035 and 2040 respectively.

\section{CONCLUSION}

The dynamics of the Remote Sensing and Geospatial Information System techniques were demonstrated in this research. The data were effectively utilized to achieve the research aim using stated objectives, other method of determining and monitoring temperatures can be used to validate the research findings, also an effective urban development and physical planning laws should be put in place to regulated urban development and clustered settlement while encouraging urban dwellers on the need for urban - rural migration, afforestation and other activities that will reduce this temperature.

\section{REFERENCES}

[1] Akbari, H. (2005). Energy Saving Potentials and Air Quality Benefits of Urban Heat Island Mitigation. United States.

[2] Anastasios P., Mavrakou, T., and Cartalis, C. (2018). Quantifying the Trends in Land Surface Temperature and Surface Urban Heat Island Intensity in Mediterranean Cities in View of SmartUrbanization" Urban Sci. 2, no. 1: 16. https://doi.org/10.3390/urbansci2010016

[3] Chuvieco, E. and Huete, A. (2010) Fundamentals of satellite remote sensing. CRC Press Inc. Boca Raton, FL 33487, USA.

[4] Collier, C.G. (2006). The impact of urban areas on weather. Meteorol. Soc. 132, 1-25.

[5] Chuyuan, W. S. W. (2016). Spatio-Temporal Modeling of the Urban Heat Island. (R. M Thenkabail, Ed.) remote sensing, 8, 185.

[6] Elachi, C. and Van Z. J. (2006). Introduction to the physics and techniques of remote sensing. Second edn. Hoboken, NJ, USA: John Wiley \& Sons.

[7] EPA. (2019). Heat Island Impacts. Retrieved March 12, 2019, from https://www.epa.gov/heatislands/heat-island-impacts

[8] Favretto, A. (2018). Urban Heat Island analysis with Remote Sensing and GIS methods: an application in the Trieste area ( North-East of Italy ). Bollettino Della Società Geografica Italiana Serie, 1(1), 215-229. https://doi.org/10.13128/bsgi.v1i1.101

[9] Mohajerani, A., Bakaric, J., \& Jeffrey-Bailey, T. (2017). The urban heat island effect, its causes, and mitigation, with reference to the thermal properties of asphalt concrete. Journal of Environmental Management, 197:, 522-538.

[10] Nor A. A., Nur F. F. N., Siti A. S. and Zulkiflee A. L., (2015). Utilizing LANDSAT imageries for Land Surface Temperature (LST) analysis. Penang IslandLangkawi, Malaysia

[11] Ngie, A., Abutaleb, K., Ahmed, F., Darwish, A., \& Ahmed, M. (2014). Assessment of urban heat Island using satellite remotely sensed imagery : a review. South African Geographical Journal.https://doi.org/10.1080/03736245.2014.924864 from http://scholarcommo ns.usf.edu/etd/3250.

[12] NIMET, (2011). Nigeria Climate Review Bulletin, pp. 1-40.

[13] Obiefuna, J. N., Nwilo, P. C., Okolie, C. J., Emmanuel, E. I., \& Daramola, O. (2018). Dynamics of Land Surface Temperature in Response to Land Cover Changes in Lagos Metropolis. Nigerian Journal of Environmental Sciences and Technology, 2(2), 148-159

[14] Oke, T. R. (1988). City size and the urban heat island. Atmospheric Environment, 7(8), 769779.

[15] Olaleye J.B. (2016). Lecture note on Advanced Remote Sensing, Surveying and Geomatics Department, Rivers State University

[16] Oltra-Carrio, R, Sobrino, J. A., Franch, B., and Nerry, F. (2012). Land surface emissivity retrieval from airborne sensor over urban areas. Remote Sens. Environ.123, 298-305.

[17] Opuaji, A.T. (2020). Advanced Mathematical Method and Adjustment, Surveying and Geomatics Department, Rivers State University. (Unpublished)

[18] Rinkesh. V. (2019). What is Urban Heat Island? Retrieved from on 8th of April 2021 from https://www.conserve-energyfuture.com/effects-solutions-urban-heatisland.php

[19] Salama, M. S., Van der Velde, R., Zhong, L., Ma, Y., Ofwono, M., \& Su, Z. (2012). Decadal Variations of land surface temperature anomalies observed over the Tibetan Plateau by the Special Sensor Microwave Imager (SSM/I) from 1987 to 2008. Climatic Change, 114(3-4), 769-781. doi: 10.1007/s10584-012-0427-3.

[20] United Nation, (2018). World population forecast. Retrieved March 2, 2021, From; https://www.un.org/development/desa/en/news/population/2018-revisionofworld-urbanization-prospects.html

\section{AUTHORS}

First Author - Eze, Promise Ikenda is a Research Scientist in Academics, He is presently a lecturer in the Department of Surveying and Geomatics, Faculty of Environmental Sciences, Rivers State University, Nigeria. He holds a Bachelor of Technology and Masters of Science in Surveying and Geomatics Degrees. His Research interest is in Surveying and Environmental Mapping, Remote Sensing, Land Administration, Photogrammetry and Numerical and Analytical Methods.

Second Author - Lawson Nwidum is a Master degree Students in Remote Sensing and GIS, Rivers State University. He holds a HND and PGD degrees in surveying and geomatics. His research interest is in Environmental mapping, Remote Sensing, Cartography, Land information and database management system. 
International Journal of Scientific and Research Publications, Volume 11, Issue 10, October 2021

This publication is licensed under Creative Commons Attribution CC BY. 